\title{
Cefalea como presentación clínica de neurocisticercosis
}

\author{
Amparo Manzano Juárez ${ }^{a}$, María Pilar Martínez Garcíaa, María José Martínez Andrés ${ }^{a}$ \\ y María Pilar Sánchez Betetab.
}

\begin{abstract}
${ }^{a}$ M.I.R. Medicina de Familia y Comunitaria. Centro de Salud Hellín II. Albacete (España). ${ }^{\mathrm{b}}$ Médico de Familia. Centro de Salud Tobarra. Albacete (España).
\end{abstract}

\section{Correspondencia: Amparo Manzano Juárez. C/ Jacinto Benavente 19, $4^{\circ} \mathrm{V}$. C.P. 02400. Hellín (Albacete). España.}

Correo electrónico: ampamanjua@hotmail.com.

Recibido el 26 de septiembre de 2014.

Aceptado para su publicación el 30 de octubre de 2014.

\section{RESUMEN}

La neurocisticercosis es la enfermedad parasitaria más frecuente del sistema nervioso central. Su frecuencia en nuestro país ha ido aumentando por los movimientos migratorios. Presentamos el caso de una mujer de 58 años, natural de Ecuador, con antecedentes personales de cefalea recurrente, que acude al Servicio de Urgencias por cefalea hemicraneal diaria que no cede con analgésicos habituales. El diagnóstico de presunción se determina en Urgencias tras una correcta anamnesis y pruebas complementarias, siendo confirmado en el Servicio de Neurología.

Palabras Clave: Eosinofilia. Neurocisticercosis. Cefalea.

\section{ABSTRACT}

Headache as clinical presentation of neurocysticercosis

Neurocysticercosis is the most common parasitic disease of the central nervous system. Its frequency in our country has increased due to migratory movements. We report the case of a 58-year-old woman from Ecuador, with a history of recurrent headache, presented to the Emergency Department with daily hemicranial headache that does not respond to common analgesics. The presumptive diagnosis is determined in the emergency room after a correct anamnesis and laboratory tests, being confirmed in the Neurology Department.

Key words: Eosinophilia. Neurocysticercosis. Headache.

\section{INTRODUCCIÓN}

La cefalea se puede clasificar en primaria y secundaria según las características clínicas, analíticas y radiológicas. Nuestra paciente presenta cefalea con características típicamente migrañosas, pero hay que descartar un posible secundarismo debido a la evolución del proceso y las características epidemiológicas ${ }^{1}$.

La cisticercosis es una enfermedad endémica de América del Sur y Central, Asia y África Subsahariana. En los últimos 20 años, en España ha pasado de ser una enfermedad de carácter autóctono a ser una infección casi exclusivamente importada. Debido al fenómeno migratorio y al ser la enfermedad parasitaria más importante del sistema nervioso central y causa más frecuente de epilepsia adquirida en países en vías de desarrollo, debemos tenerla en cuenta dentro del diagnóstico diferencial de cefalea crónica, especialmente en pacientes procedentes de áreas endémicas ${ }^{1-4}$. 


\section{CASO CLÍNICO}

Paciente de 58 años, con historia de cefalea recurrente, motivo por el que fue vista en tres ocasiones en los últimos 4 meses en el Servicio de Urgencias. Con un primer diagnóstico de cefalea tensional recurrente y sucesivos de cefalea migrañosa, se inició tratamiento analgésico de primer escalón y como adyuvantes benzodiacepinas y triptanes. Acude de nuevo por cuadro de 7 días de evolución de cefalea hemicraneal pulsátil que no cede con el tratamiento anterior. Se acompaña de fotofobia, náuseas y vómitos. La paciente es natural de Ecuador, reside en España desde hace 7 años y viajó a su país hace unos meses. Actualmente trabaja en la agricultura y no ha tenido contacto con animales. Niega consumo de tóxicos.

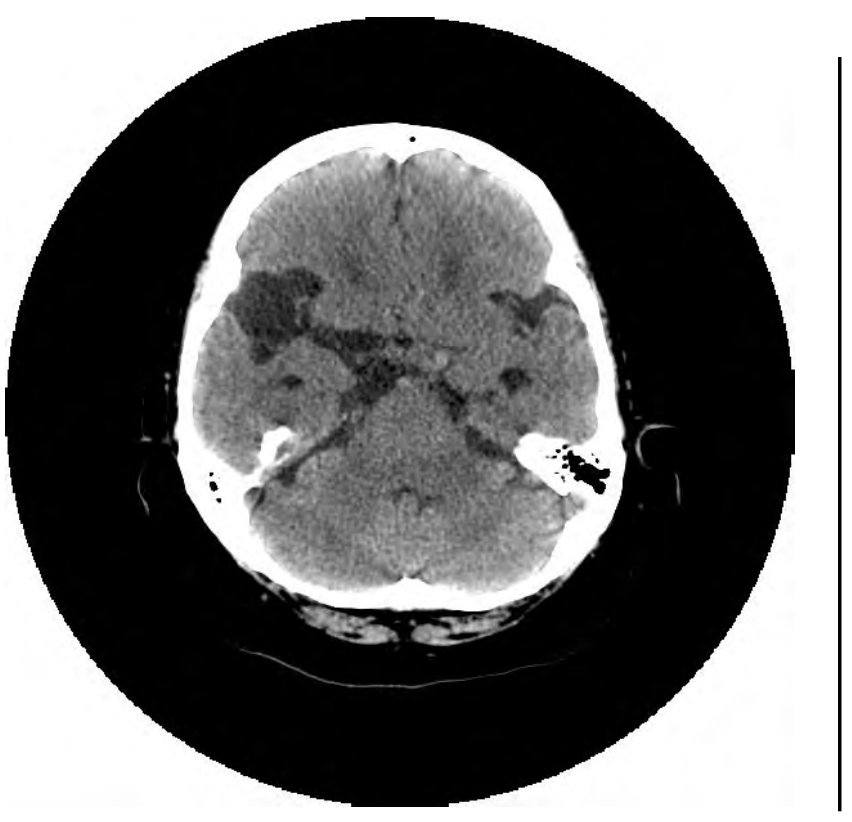

Como antecedentes personales destaca tuberculosis hace 20 años, que fue tratada en su país, y cefalea tipo mixta de años de evolución en tratamiento con analgésicos, antidepresivos, triptanes y ansiolíticos.

La exploración neurológica completa no mostró ninguna alteración. Se realizó un fondo de ojo, que era normal, y la campimetría no presentaba alteraciones significativas. El resto de exploración fue normal. En la analítica de urgencia destaca una discreta eosinofilia $(9,3 \%)$. Dada la clínica se realiza una tomografía axial computarizada (TAC) craneal $^{5}$ con resultado de hidrocefalia moderada de predominio triventricular, con IV ventrículo permeable y discretos signos de exudado transependimario. Dilatación quística extraaxial en el espacio subaracnoideo silviano derecho y supraselar (figuras 1 y 2 ).

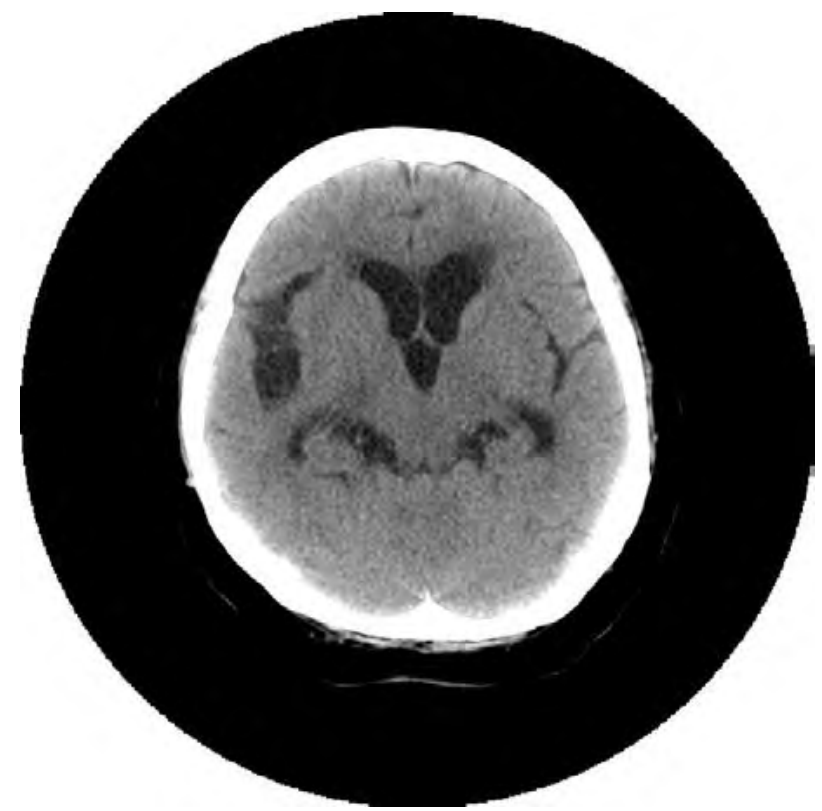

Figuras 1 y 2. Tomografía axial computerizada craneal. Hidrocefalia moderada de predominio triventricular, con IV ventrículo permeable y discretos signos de exudado transependimario. Dilatación quística extraaxial en el espacio subaracnoideo silviano derecho y supraselar.

En el Servicio de Urgencias se pautó gastroprotección y analgésicos de primer, segundo y tercer escalón con leve mejoría clínica. Tras el resultado del TAC y el tratamiento refractario, se realiza interconsulta a Neurología, que indica traslado de la paciente al Hospital de referencia e ingreso en su servicio. Se le realiza una batería de pruebas:

- Resonancia Magnética (RM): hallazgos compatibles con neurocisticercosis racemosa lo- calizada en cisura de Silvio derecha, temporal anterior, que se extiende a las cisternas por delante del tronco del encéfalo y perimesencefálica. Aumento de tamaño del tercer ventrículo y laterales, con exudados periventriculares, compatible con hidrocefalia activa (figura 3 ).

- Doppler orbitario: se objetivan signos de hipertensión intracraneal. 
- Radiografía simple de ambos muslos (para descartar presencia de cisticercos a nivel muscular y subcutáneo): no se aprecian calcificaciones musculares.

- Serología/PCR cisticerco positivo, con lo que se confirma el diagnóstico.

Se inició tratamiento con corticoides en pauta descendente y albendazol, con buena respuesta. No precisó realizar derivación de líquido cefalorraquídeo.

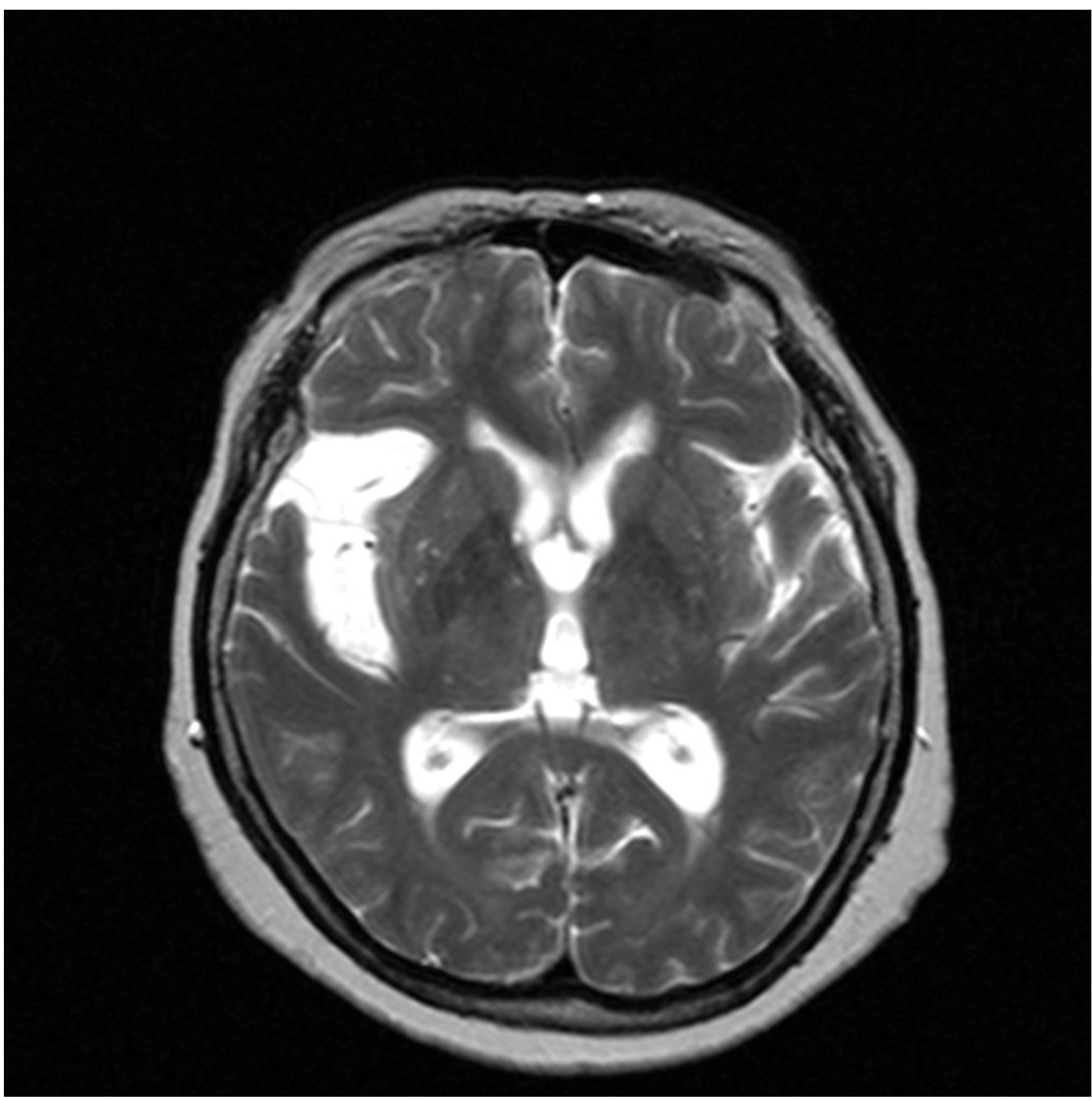

Figura 3. Resonancia magnética craneal. Hallazgos compatibles con neurocisticercosis racemosa localizada en cisura de Silvio derecha, temporal anterior, que se extiende a las cisternas por delante del tronco del encéfalo y perimesencefálica. Aumento de tamaño del tercer ventrículo y laterales, con exudados periventriculares, compatible con hidrocefalia activa. 


\section{DISCUSIÓN}

La neurocisticercosis (NC) es una parasitosis humana causada por las larvas de la Taenia solium, que es la que con mayor frecuencia afecta al Sistema Nerviosos Central (SNC). En la infección humana por $T$. solium se distingue la teniasis y la cisticercosis. El ser humano, que es el único huésped definitivo, adquiere la teniasis cuando come carne de cerdo cruda o poco cocinada, que contiene cisticercos (larvas enquistadas). La cisticercosis y, por tanto, la NC, la adquieren tanto el ser humano como el cerdo, que pueden actuar como huéspedes intermediarios, cuando ingieren huevos de $T$. solium (contaminación feco-oral). Los huevos atraviesan la pared intestinal y a través de la sangre se depositan en su forma larvaria o cisticercos en los distintos tejidos. Las localizaciones más frecuentes son el SNC, los ojos, los músculos y el tejido subcutáneo, y se pueden diagnosticar biopsiando los nódulos que se palpan o mediante radiografía si las lesiones están calcificadas y no son palpables².

Centrándonos en la NC, cuando los cisticercos se establecen en el SNC pueden permanecer viables durante décadas, cursando de forma asintomática o desencadenando una reacción inflamatoria que condiciona cambios en el interior del parásito y el tejido nervioso adyacente; esta reacción inflamatoria propicia la muerte del cisticerco y su posterior trasformación a nódulo calcificado. La manifestación clínica es muy variable y depende de la aparición de la respuesta inmunológica del huésped, de la localización de quistes (formas parenquimatosas y extraparenquimatosas - subaracnoidea, ventricular, espinal y mixta -) y del estadio y el número de éstos ${ }^{6}$. El motivo de consulta más frecuente es la aparición de una crisis convulsiva, seguida de cefalea y otros síntomas de hipertensión intracraneal (aunque poco frecuentes). La exploración neurológica habitualmente es normal.

El diagnóstico de NC se basa en pruebas de imagen (TAC y RM), que muestran lesiones quísticas localizadas en el parénquima cerebral, espacios subaracnoideos, ventrículos o canal espinal; y por técnicas serológicas como ELISA e inmunoblot.
El tratamiento se basa en albendazol a dosis de 15 $\mathrm{mg} / \mathrm{kg} /$ día durante 7-30 días o praziquantel 50-75 $\mathrm{mg} / \mathrm{kg} /$ día durante 14 días y corticoides en pauta descendente de forma conjunta para disminuir la inflamación producida por la muerte del parásito. Se recurre a la cirugía en casos con hidrocefalia o quistes intraventriculares. La NC, si es intraparenquimatosa, con una carga de cisticercos baja, tiene buen pronóstico. El tratamiento antiparasitario disminuye la recurrencia de convulsiones. Pero si se trata de la forma extraparenquimatosa presenta un mal pronóstico, porque los quistes subaracnoideos racimosos basales se asocian a una intensa inflamación, hidrocefalia, pérdida de visión e infartos cerebrales. El riesgo de muerte es mayor en pacientes con hipertensión endocraneana y con carga parasitaria elevada. Es primordial la educación para la salud cuando se tiene un paciente con cisticercosis y la búsqueda de nuevos casos familiares ${ }^{1-4,7-9}$.

\section{BIBLIOGRAFÍA}

1. Muro A, Andrade MA, Shariati F, Pérez-Arellano JL. Infecciones por cestodos. Medicine. 2010; 10 (55): 3707-16.

2. Sarria Estrada S, Frascheri Verzelli L, Siurana Montilva S, Auger Acosta C, Rovira Cañellas A. Neurocisticercosis. Hallazgos radiológicos. Radiología. 2013; 55 (2): 130-41.

3. Terraza S, Pujol T, Gascón J, Corachán M. Neurocisticercosis: ¿Una enfermedad importada? Med Clin (Barc). 2001; 116 (7): 261-

4. Ortega-Herrera R, Fernández- Segura ME, Gómez de Travecedo y Calvo I. Inmigrante ecuatoriana con cefalea. Enferm Infecc Microbiol Clin 2004; 22 (4):248-9.

5. Huerta Villanueva M. Mujer de 51 años con cefalea crónica diaria. Medicine. 2011; 10 (70): 4791e1-e3.

6. Ruiz S, García-Vázquez E, Picazo R, Hernández A, Herrero JA, Gómez J. La neurocisticercosis en Murcia. Rev Clin Esp. 2011; 211 (3): 133-8.

7. Chater Cure G, García Roldán N, Peña Quiñones G, Dau Costa A, Bermúdez S, Hakim F et al. Neurocisticercosis. Acta Neurol Colomb. 2009; 25 (1): 42-53.

8. Martínez Pérez J, Caldevilla Bernardo D, Villena Ferrer A. Neurocisticercosis, una causa infrecuente de cefalea. Semergen. 2005; 31 (6): 284-5.

9. Cañizares R, Roig P, Esparcia A, Zorraquino A, Ortiz de la Tabla V, Merino J. Cuadro convulsivo en paciente joven. Rev Clin Esp. 2003; 203 (12): 601-3. 